\title{
Hepatic arterial infusion in hepatocellular carcinoma: a single center experience
}

\author{
Bohuslav Melichara, ${ }^{\text {af }}$, Josef Dvorak ${ }^{c}$, Alexander Ferko ${ }^{b}$, Katerina Kamaradovad ${ }^{d}$, Antonin Krajina ${ }^{e}$
}

\begin{abstract}
Aim. The aim of the present study was to evaluate a single center experience with hepatic arterial infusion (HAl) in patients with hepatocellular carcinoma.

Methods. A retrospective analysis of 20 patients treated for hepatocellular carcinoma between 1994 and 2007.

Results. Most patients were treated with an $\mathrm{HAl}$ of doxorubicin and cisplatin combined with 5-fluorouracil and folinic acid. The response was not evaluable in the majority of patients, predominantly because of associated surgical procedure or because only one cycle of HAl was administered. The median progression-free survival was 7.7 months. The median survival of all patients was 12.2 months (5-year survival 5\%). Serious adverse events were observed in 5 patients, and one patient died of liver failure in association with the administration of HAI.
\end{abstract}

Conclusion. The data show the limited efficacy of HAI in patients with hepatocellular carcinoma.

Key words: hepatic arterial infusion/hepatocellular carcinoma

Received: May 28, 2014; Accepted with revision: October 8, 2014; Available online: November 11, 2014 http://dx.doi.org/10.5507/bp.2014.054

${ }^{a}$ Department of Oncology, Faculty of Medicine and Dentistry, Palacky University Olomouc, Czech Republic ${ }^{b}$ Department of Surgery, Faculty of Medicine in Hradec Kralove, Charles University in Prague and University Hospital Hradec Kralove 'Department of Oncology and Radiotherapy, Faculty of Medicine in Hradec Kralove, Charles University in Prague and University Hospital Hradec Kralove

${ }^{d}$ The Fingerland Institute of Pathology, Faculty of Medicine in Hradec Kralove, Charles University in Prague and University Hospital Hradec Kralove

${ }^{e}$ Department of Radiology, Faculty of Medicine in Hradec Kralove, Charles University in Prague and University Hospital Hradec Kralove ${ }^{f} 4^{\text {th }}$ Department of Internal Medicine - Hematology, Faculty of Medicine in Hradec Kralove, Charles University in Prague and University Hospital Hradec Kralove

Corresponding author: Bohuslav Melichar, e-mail: bohuslav.melichar@fnol.cz

\section{INTRODUCTION}

In contrast to East $\mathrm{Asia}^{1}$, the incidence of hepatocellular carcinoma (HCC) is relatively low in Western countries $^{2}$. The liver is frequently involved in the metastatic spread of tumors of different primary locations, and in the West, liver metastases represent by far the most common form of liver cancer. Some aspects of the management of liver tumors, primary or metastatic, are similar across the spectrum of primary sites. In general, the best results are obtained with therapeutic procedures that are targeted to the liver, e.g. liver resection, radiofrequency ablation or, in the case of HCC, liver transplantation ${ }^{3}$. Optimal results with liver-targeted approaches are to be expected in patients with disease limited to the liver. For obvious reasons, patients with primary liver tumors are candidates for a liver-directed approach more frequently than patients with tumors of other primary sites.

One therapeutic approach that has been studied extensively in patients with both primary and metastatic liver tumors is hepatic arterial infusion (HAI). HAI uses anatomical targeting of cytotoxic agents to achieve higher intratumoral drug concentration with less systemic toxicity ${ }^{4}$. HAI has been best studied in patients with common tumors metastatic to the liver, e.g. colorectal carcinoma. In patients with colorectal carcinoma metastatic to the liv- er it has been demonstrated that the postulated theoretical advantage of higher intratumoral drug concentration and lower toxicity indeed translates into superior outcomes such as response rate, but it has been more difficult to demonstrate an overall survival benefit. Consequently, the use of HAI in colorectal cancer metastatic to the liver has always been somewhat controversial and has markedly decreased with the advent of new targeted agents ${ }^{4}$. The potential role of HAI in patients with other primary tumors involving the liver is even less clear. Promising results were reported in patients with liver metastases of uveal melanoma $\mathrm{a}^{5}$ and patients with biliary tract carcinoma ${ }^{6}$. While chemoembolization, another liver-directed procedure targeting the vasculature, is a standard method in the management of patients with inoperable $\mathrm{HCC}$ based on the results of prospective trials indicating survival benefit ${ }^{7}$, the utilization of HAI in this setting is less frequent. Numerous studies on HAI in HCC have been reported from East Asia, especially from Japan ${ }^{8-20}$, but the experience with this approach in the Caucasian population of Western countries is very limited ${ }^{21,22}$. The use of HAI is currently not recommended in therapeutic guidelines, but this approach has been used in the past. We present here a retrospective analysis of a single center historical experience with HAI in patients with HCC. 


\section{PATIENTS AND METHODS}

A retrospective analysis was performed of all consecutive patients with histologically verified HCC treated with at least one course of HAI at the Faculty of Medicine in Hradec Kralove, Charles University in Prague and University Hospital Hradec Kralove, Czech Republic between December 1994 and April 2007. The patient charts were searched for relevant information. Survival was evaluated from the start of HAI to death. No patients were lost to follow up. Since the staging classification of primary liver tumor has changed repeatedly over the time during which the patients in the present cohort were treated ${ }^{23}$, all cases were restaged according to the Barcelona Clinic Liver Cancer (BCLC) staging classification ${ }^{24}$ to ensure comparability of the results between individual patients.

HAI was administered through catheters with a subcutaneous port system implanted either surgically during an open procedure or percutaneously, or through catheters introduced via femoral artery by the Seldinger technique as described earlier ${ }^{6}$. The regimens used included HAI of folinic acid (50-150 mg bolus or short infusion) and 5-fluorouracil $\left(400 \mathrm{mg} / \mathrm{m}^{2}\right)$ for $2-4 \mathrm{~h}$ on days $1-5$ every 4 weeks or, in one patient, on day 1 weekly; HAI of folinic acid (50-200 mg bolus or short infusion), 5-fluorouracil $\left(750 \mathrm{mg} / \mathrm{m}^{2}\right)$, cisplatin $\left(25 \mathrm{mg} / \mathrm{m}^{2}\right)$ and doxorubicin $(15$ $\mathrm{mg} / \mathrm{m}^{2}$ ) for 3-24 h on days 1-3 every 3-4 weeks; or HAI of folinic acid (50-200 $\mathrm{mg}$ bolus or short infusion), 5-fluorouracil $\left(750 \mathrm{mg} / \mathrm{m}^{2}\right)$ and cisplatin $\left(20 \mathrm{mg} / \mathrm{m}^{2}\right)$ for $24 \mathrm{~h}$ on days 1-3 every 4 weeks. Premedications that included intravenous injection of a setrone antiemetic (usually granisetrone), short infusion of dexamethasone $(16 \mathrm{mg})$ and adequate intravenous hydration were also administered. Continuous 24-h administration of HAI was possible only during hospital stay, and in patients treated on an outpatient basis the duration of HAI was shorter (2-4 h). In a second- and third-line setting, HAI of interferon-alpha2a (Roferon) 9 MU for $1 \mathrm{~h} 3$ times a week, interferon-alpha2b (Intron) $10 \mathrm{MU}$ for slow bolus 3 times a week, melphalan $15 \mathrm{mg} / \mathrm{m}^{2}$ for $2 \mathrm{~h}$, or dexamethasone 16 mg slow bolus 3 times a week were administered.

The response was evaluated by imaging studies using the standard World Health Organization criteria ${ }^{25}$. Descriptive statistics were used to characterize the present retrospective cohort of patients. Overall survival and progression-free survival (PFS) were calculated using the Kaplan-Meier method. The differences in survival were examined using the log-rank test. The statistical analyses were performed using NCSS software (Number Cruncher Statistical Systems, Kaysville, UT, USA).

\section{RESULTS}

Twenty patients, 19 males and one female, aged (mean \pm standard deviation) $59 \pm 10$ (range 44-76) years, with histologically verified HCC were treated with at least one cycle of HAI. All patients were Caucasians. Six patients had BCLC stage A disease, 6 patients had BCLC stage B and 8 patients had BCLC stage $C$ tumors. Four patients had extrahepatic spread. Five patients had a surgical cytoreductive procedure immediately prior or shortly after the start of HAI, including 3 patients in whom the surgery was considered radical. Two patients had Child-Pugh B liver cirrhosis, while the remaining 18 patients were functionally of Child-Pugh A class. The median sum of the largest diameters of evaluable lesions in patients with unresectable tumors was $100 \mathrm{~mm}$ (range $40-260 \mathrm{~mm}$ ); the median number of lesions was 3 (range 1->10). All 3 patients with resected tumors had single lesion, median of the largest diameter was $60 \mathrm{~mm}$ (range 40-65 mm).

The median time from diagnosis to the start of HAI was 52 days. The catheters for HAI were implanted surgically in 11 cases. In 7 of these patients a course of HAI was administered before the surgical implantation through single-use catheter inserted by the Seldinger method. In two cases permanent catheters were implanted percutaneously by an interventional radiologist. Seven patients had HAI administered only through single-use catheters inserted using the Seldinger method.

In the first-line setting, 14 patients were treated with an HAI combination of doxorubicin, cisplatin, 5-fluorouracil and leucovorin, 5 patients were treated with an HAI of 5-fluorouracil and leucovorin and one patient was treated with an HAI combination of cisplatin, 5-fluorouracil and leucovorin. The median number of cycles administered in the first-line treatment was 4 (range 1-26). Six patients were treated by only one course of HAI. The median daily dose of 5-fluorouracil was $533 \mathrm{mg} / \mathrm{m}^{2}$, median daily dose of cisplatin was $19 \mathrm{mg} / \mathrm{m}^{2}$ and median daily dose of doxorubicin was $15 \mathrm{mg} / \mathrm{m}^{2}$. Stable disease as the best response was observed in 7 patients, and progressive disease was noted in 2 patients. The response was not evaluable in 11 patients, mostly because of prior surgical procedure, or because only one course of HAI was administered. Among the 9 patients with evaluable response, increased (>13 IU/mL) alpha-fetoprotein (AFP) was present and subsequent response was evaluable in 6 patients (median pretreatment AFP concentration $10471 \mathrm{IU} / \mathrm{mL}$, mean \pm standard deviation $50038 \pm 94675 \mathrm{IU} / \mathrm{mL}$, range 22-240670 $\mathrm{IU} / \mathrm{mL}$ ). Among these 6 patients, AFP increased after therapy (by $119 \%$ and $991 \%$ ) in two patients who were classified as having stable disease, and decreased by a median of $63 \%$ (range $26-98 \%$ ) in the remaining 4 patients, including 3 patients with stable disease and one patient with progressive disease (in two patients after a transient surge). In the patient with progressive disease, AFP decreased by $26 \%$ after an initial surge, but increased by $189 \%$ compared to baseline 6 weeks after the nadir. In an additional patient whose response was not evaluable because only a single course of HAI was administered AFP decreased by $88 \%$, and the decrease continued during subsequent systemic therapy.

Four patients were treated with a second-line HAI regimen, including two patients treated with an HAI of interferon-alpha, one patient treated with HAI of dexamethasone and one patient treated with an HAI of cisplatin, 5-fluorouracil and leucovorin. The third line regimen was administered in 3 patients, including one patient treated with an HAI of melphalan, one patient treated 
with an HAI of dexamethasone and one patient treated with an experimental therapy (adoptive immunotherapy using autologous cultured leukocytes). None of the patients responded to second or third line HAI therapy. Eight patients received further systemic therapy.

Serious adverse events that required hospitalization occurred in 5 patients. In three of these patients the course was complicated by catheter occlusion, including one patient who also had grade 3 thrombocytopenia. One patient had febrile neutropenia, and one patient with Child-Pugh B cirrhosis died of liver failure after HAI. This death was the only fatal event associated with the administration of therapy.

At the time of the analysis, all patients had progressed and died. The median PFS was 7.7 months (1-year PFS 20\%, 2-year PFS 15\%, 3-year PFS 5\%, 4-year PFS 5\% and 5 -year PFS 5\%; Fig. 1). The median overall survival of all patients was 12.2 months (1-year survival 55\%, 2-year survival 20\%, 3-year survival 10\%, 4-year survival 5\% and 5-year survival 5\%; Fig. 1). The PFS and overall survival in patients who had cytoreductive surgery immediately prior or shortly after the start of HAI (7.5 months and 10.3 months, respectively) were not significantly different from patients who had no surgical cytoreductive procedure (10.0 months and 12.9 months, respectively). The PFS (median 8.9, 10.4 and 5.7 months, respectively) and overall survival (median 16.9, 20.3 and 10.9 months, respectively) were not significantly different from patients with BCLC stage A, B and C.

\section{DISCUSSION}

The results demonstrate the limited efficacy of HAI in HCC. While comparison of results across studies is inherently problematic, the median survival from the start of therapy of 12 months in the present cohort is generally comparable to the reported survival of patients treated with targeted therapy or chemoembolization ${ }^{26,27}$. Moreover, the results obtained in the present small cohort of Western patients are similar to the outcomes reported with HAI in HCC patients from the East ${ }^{8,9,14,16}$. The response rate in most patients in the present cohort was not evaluable. Therefore survival, rather than objective response rate, was the principal parameter of efficacy evaluated in the present retrospective study. The survival data are definitive in the present cohort and overall survival represents the best estimate of treatment efficacy in a patient population that was selected less strictly than in a prospective clinical trial. Objective response and progression-free survival, although frequently used in clinical trials, are only surrogates for overall survival.

Because HCC is a relatively uncommon tumor, and associated liver cirrhosis often precludes administration of chemotherapy, the data on the efficacy of cytotoxic agents, both administered systemically or as HAI, are relatively limited compared to other tumors. The efficacy of systemic chemotherapy is, in general, considered to be limited ${ }^{28}$. Among vascular liver-directed therapeutic methods, chemoembolization has been the approach used by far most widely in $\mathrm{HCC}$ in Western countries ${ }^{27}$, while the use of HAI dominated in East Asia ${ }^{13}$. However, even in Japan before the advent of targeted therapy generally less than $5 \%$ of HCC patients were treated with HAI (ref. ${ }^{13}$ ).

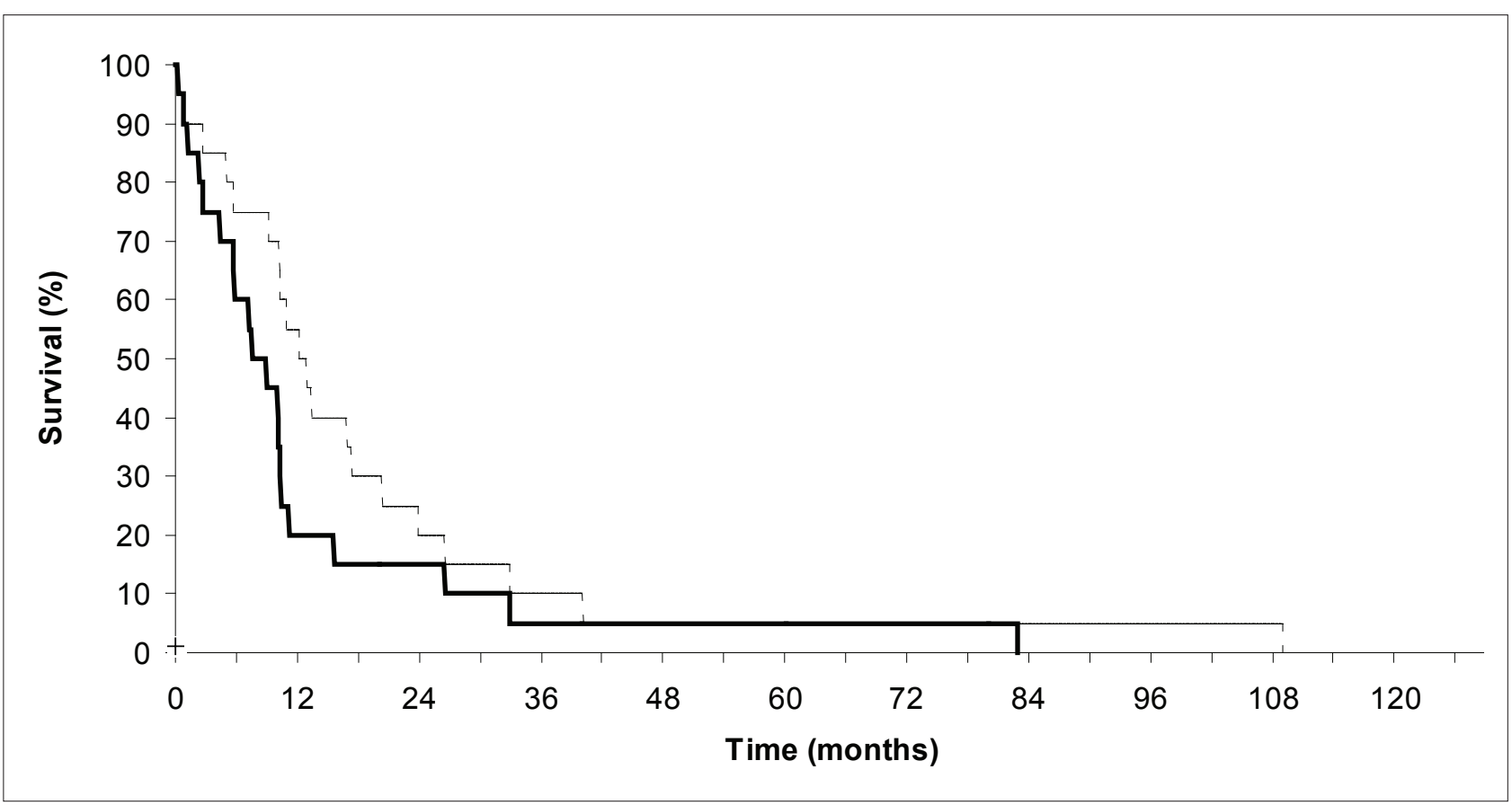

Fig. 1. Progression-free survival (full line) and overall survival (dashed line) of patients in the present cohort. Shown is the progression-free survival (median 7.7 months; full line) and overall survival (median 12.2 months; dashed line) of patients with HCC treated with HAI in the present cohort. 
Although more prospective studies are available supporting the use of chemoembolization ${ }^{7}$, a recent randomized clinical trial reported similar efficacy of HAI compared to chemoembolization ${ }^{18}$. On the other hand, the efficacy of HAI in patients progressing on chemoembolization seems to be limited ${ }^{15}$.

While the experience with HAI in the West is limited $^{21,22}$, many studies on HAI have been reported from East Asia, especially Japan. A number of prospective trials and retrospective series have reported the results of HAI in Asian patients with hepatocellular carcinoma ${ }^{8,9}$. The efficacy and tolerance of HAI in Asian HCC patients has also been reviewed recently ${ }^{10-13,29}$. Despite the fact that different cytotoxic agents have been used across the spectrum of different primary tumors, 5-fluoro-2'-deoxyuridine (floxuridine) has been traditionally regarded as an optimal agent for HAI. However, the experience with floxuridine in HCC is more limited ${ }^{9}$. In addition to fluoropyrimidine (mostly 5 -fluorouracil) monotherapy ${ }^{29}$, the combination of 5-fluorouracil and cisplatin has been the most commonly used HAI regimen in HCC (ref. ${ }^{8,14,16,17,20}$ ). The efficacy of HAI of 5-fluorouracil/cisplatin combination seems to be higher than HAI of 5-fluorouracil alone ${ }^{17}$. Both an HAI of 5-fluorouracil and 5-fluorouracil/cisplatin combination have been combined with systemic interferon-alpha ${ }^{12,20,30,31}$. Moreover, higher dose of cisplatin and 5-fluorouracil administered as HAI results in increased response rate ${ }^{20}$. The use of anthracyclines, mitomycin $\mathrm{C}$ and etoposide has also been reported in HAI regimens in HCC (ref. ${ }^{12,22}$ ). In a retrospective analysis comparing the outcomes of 476 patients treated with HAI with 1466 patients who did not receive any active therapy, survival was reported to be significantly prolonged in patients treated with HAI (ref. ${ }^{14}$ ). Significant survival benefit was still evident when patients treated with HAI were matched with untreated patients using propensity score.

Following the demonstration of survival benefit over placebo ${ }^{26}$, sorafenib rapidly became established as the standard of care for patients with inoperable HCC. However, the efficacy of sorafenib is limited, with the median progression-free survival being around 5 months, and there remains an unmet medical need for additional effective therapies for HCC. Moreover, the considerable cost of the medication may limit the use of sorafenib, especially in low-income populations. Of note, HAI has been reported to be active in patients failing sorafenib ${ }^{32,33}$, while the activity of sorafenib has also been described in patients progressing on HAI (ref. ${ }^{34}$ ). Thus, even in the era of targeted therapy, HAI may still be an option to be considered in selected patients with disease limited to the liver and progressing on sorafenib. In fact, in a small comparative study the outcome of patients treated with HAI using the combination of cisplatin and 5-fluorouracil was comparable to sorafenib ${ }^{35}$. Obviously, the pilot experience with HAI in patients pre-treated with sorafenib will require additional confirmatory studies.

The toxicity of systemic anticancer therapy, e.g. gastrointestinal toxicity induced by cytotoxic drugs ${ }^{36}$, and side effects accompanying the administration of targeted agents ${ }^{37}$ have major impact on the quality of life. Some side effects may be less expressed with HAI compared to systemic therapy. It has been demonstrated in patients with metastatic colorectal carcinoma that HAI is associated with improved quality of life ${ }^{38}$. On the other hand, HAI may result in increased hepatotoxicity. Although liver toxicity of agents administered as HAI is in most cases limited, liver cirrhosis that is present in most HCC patients increases the risk of severe liver toxicity. Although HAI was well-tolerated in most patients treated in the present retrospective cohort, in individual patients, severe toxicity linked to HAI was observed, including one case of lethal toxicity that was caused by liver failure in a patient with Child-Pugh B liver cirrhosis.

The present report has several limitations, including small size of the cohort and its retrospective nature. In addition, an important proportion of the patients received only one course of HAI or had extrahepatic metastases. Thus, the effect of HAI may have been attenuated in the described retrospective cohort of patients because of inclusion of patients who were not optimal candidates for this therapy. Moreover, the patients might have been under-staged. Thus, it is not surprising that slightly better results were observed in some more strictly selected cohorts of patients enrolled in prospective studies of HAI in HCC. On the other hand, the present series reflects the real world practice of a relatively rarely used treatment in a disease that is also relatively rare. The standard of care has evolved since the patients in the present series were treated. Patients treated with HAI in the present series included those who had undergone liver resection. The benefit of adjuvant therapy was a matter of debate at the time, but these patients were perceived to be at high risk of recurrence. In fact, the disease recurred shortly in all 3 patients treated with radical resection. With the availability of positron emission tomography/computed tomography (PET/CT) extrahepatic disease may be more reliably identified before the start of treatment, resulting in better patient selection, offering potentially better results in the future. Similarly, other patients with BCLC stage A and B would have now been probably managed differently.

Predictive biomarkers play an increasingly important role in medical oncology $y^{39}$, but, unfortunately, there is currently no information on clinical, pathological or laboratory predictive factors and/or biomarkers that might help in identifying HCC patients likely to benefit from HAI. One important set of biomarkers is associated with the immune response. The immune system plays an important role in the control of malignant tumors. It has been documented that the systemic immune activation that is commonly observed in patients with advanced cancer ${ }^{40}$ is associated with depressed immune response ${ }^{41,42}$, and effective tumor control may enhance the host antitumor response. As mentioned above, in HCC patients the HAI of cytotoxic agents has been frequently combined with the administration of interferon-alpha ${ }^{12}$. Moreover, immunotherapy has also been studied in $\mathrm{HCC}$, including the administration of immunotherapeutic agents as HAI $\left(\right.$ ref. $\left.^{43-45}\right)$. Future studies should also investigate whether the HAI of cytotoxic agents suppresses the host immune response to a lesser extent than systemic chemotherapy. 
In conclusion, the results indicate the limited efficacy of HAI in HCC patients. HAI may still be a therapeutic option in patients with inoperable HCC and no extrahepatic spread.

\section{ACKNOWLEDGEMENT}

This study was supported by the Research Project LO1304.

Authorship contributions: All authors contributed to data collection, manuscript writing and approved final version of the manuscript.

Conflict of interest statement: The authors state that there are no conflicts of interest regarding the publication of this article.

\section{REFERENCES}

1. Han KH, Kudo M, Ye SL, Choi JY, Poon RT, Seong J, Park JW, Ichida T, Chung JW, Chow P, Cheng AL. Asian consensus workshop report: expert consensus guideline for the management of intermediate and advanced hepatocellular carcinoma in Asia. Oncology 2011;81:15864.

2. Jemal A, Bray F, Center MM, Ferlay J, Ward E, Forman D. Global cancer statistics. CA Cancer J Clin 2011;61:69-90.

3. Fraker DL, Soulen M. Regional therapy of hepatic metastases. Hem Oncol Clin N Am 2002;16:947-67.

4. Melichar B. Hepatic arterial infusion in colorectal carcinoma: Is anatomical targeting still relevant in an era of molecularly-targeted therapy? Biomed Pap Med Fac Univ Palacky Olomouc Czech Rep 2012;156:81-92.

5. Melichar B, Voboril Z, Lojik M, Krajina A. Liver metastases from uveal melanoma: clinical experience of hepatic arterial infusion of cisplatin, vinblastine and dacarbazine. Hepatogastroenterology 2009;56:1157-62.

6. Melichar B, Voboril Z, Dvorak J, Ferko A, Rozkos T, Krajina A. Hepatic arterial infusion for biliary tract carcinoma: single-center experience. Anticancer Res 2013;33:1201-8.

7. Llovet JM, Bruix J. Systemic review of randomized trials for unresectable hepatocellular carcinoma: chemoembolization improves survival. Hepatology 2003;37:429-42.

8. Park JY, Ahn SH, Yoon YJ, Kim JK, Lee HW, Lee do Y, Chon CY, Moon YM, Han KH. Repetitive short-course hepatic arterial infusion chemotherapy with high-dose 5-fluorouracil and cisplatin in patients with advanced hepatocellular carcinoma. Cancer 2007;110:129-37.

9. Baek YH, Kim KT, Lee SW, Jeong JS, Park BH, Nam KJ, Cho JH, Kim YH, Roh YH, Lee HS, Choi YM, Han SY. Efficacy of hepatic arterial infusion chemotherapy in advanced hepatocellular carcinoma. World J Gastroenterol 2012;18:3426-34.

10. Yamasaki T, Sakaida I. Hepatic arterial infusion chemotherapy for advanced hepatocellular carcinoma and future treatments for the poor responders. Hepatol Res 2012 42:340-8.

11. Ueda H, Fukuchi $H$, Tanaka C. Toxicity and efficacy of hepatic arterial infusion chemotherapy for advanced hepatocellular carcinoma (Review). Oncol Lett 2012;3:259-63.

12. Shao YY, Huang CC, Liang PC, Lin ZZ. Hepatic arterial infusion of chemotherapy for advanced hepatocellular carcinoma. Asia Pac J Clin Oncol 2010;6:80-8.

13. Yamashita T. Current status of hepatocellular carcinoma treatment in Japan. Clin Drug Investig 2012;32:15-23.

14. Nouso K, Miyahara K, Uchida D, Kuwaki K, Izumi N, Omata M, Ichida T, Kudo M, Ku Y, Kokudo N, Sakamoto M, Nakashima O, Takayama T, Matsui O, Matsuyama Y, Yamamoto K. Effect of hepatic arterial infusion chemotherapy of 5-fluorouracil and cisplatin for advanced hepatocellular carcinoma in the Nationwide Survey of Primary Liver Cancer in Japan. Br J Cancer 2013;109:1904-7.

15. Kirikoshi H, Yoneda M, Mawatari H, Fujita K, Imajo K, Kato S, Suzuki K, Kobayashi N, Kubota K, Maeda S, Nakajima A, Saito S. Is hepatic arterial infusion chemotherapy effective treatment for advanced hepatocellular carcinoma resistant to transarterial chemoembolization? World J Gastroenterol 2012;18:1933-9.

16. Kim BK, Park JY, Choi HJ, Kim do Y, Ahn SH, Kim JK, Lee do Y, Lee KH, Han KH. Long-term clinical outcomes of hepatic arterial infusion chemotherapy with cisplatin with or without 5-fluorouracil in locally advanced hepatocellular carcinoma. J Cancer Res Clin Oncol 2011;137:659-67.

17. Yamashita T, Arai K, Sunagozaka H, Ueda T, Terashima T, Yamashita T, Mizukoshi E, Sakai A, Nakamoto Y, Honda M, Kaneko S. Randomized, phase II study comparing interferon combined with hepatic arterial infusion of fluorouracil plus cisplatin and fluorouracil alone in patients with advanced hepatocellular carcinoma. Oncology 2011;81:281-90.

18. Okusaka T, Kasugai H, Shioyama Y, Tanaka K, Kudo M, Saisho H, Osaki Y, Sata M, Fujiyama S, Kumada T, Sato K, Yamamoto S, Hinotsu S, Sato T. Transarterial chemotherapy alone versus transarterial chemoembolization for hepatocellular carcinoma: a randomized phase III trial. J Hepatol 2009;51:1030-6.

19. Miyaki D, Aikata H, Honda Y, Naeshiro N, Nakahara T, Tanaka M, Nagaoki Y, Kawaoka T, Takaki S, Waki K, Hiramatsu A, Takahashi S, Ishikawa M, Kakizawa H, Awai K, Chayama K. Hepatic arterial infusion chemotherapy for advanced hepatocellular carcinoma according to Child-Pugh classification. J Gastroenterol Hepatol 2012;27:1850-7.

20. Woo HY, Bae SH, Park JY, Han KH, Chun HJ, Choi BG, Im HU, Choi JY, Yoon SK, Cheong JY, Cho SW, Jang BK, Hwang JS, Kim SG, Kim YS, Seo YS, Yim HJ, Um SH. A randomized comparative study of high-dose hepatic arterial infusion chemotherapy for intractable, advanced hepatocellular carcinoma. Cancer Chemother Pharmacol 2010;65:37382.

21. Patt YZ, Charnsangavej C, Yoffe B, Smith R, Lawrence D, Chuang V, Carrasco H, Roh M, Chase J, Fischer H. Hepatic arterial infusion of floxuridine, leucovorin, doxorubicin, and cisplatin for hepatocellular carcinoma: Effects of hepatitis B and C viral infection on drug toxicity and patient survival. J Clin Oncol 1994;12:1204-11.

22. Tzoracoleftherakis EE, Spiliotis JD, Kyriakopoulou T, Kakkos SK. Intraarterial versus systemic chemotherapy for non-operable hepatocellular carcinoma. Hepatogastroenterology 1999;46:1122-5.

23. Chung H, Kudo M, Takahashi S, Hagiwara S, Sakaguchi Y, Inoue T, Minami Y, Ueshima K, Fukunaga T. Review of current staging systems for hepatocellular carcinoma. Hepatol Res 2007;37:S210-S215.

24. Llovet JM, Fuster J, Bruix J. The Barcelona approach: diagnosis, staging, and treatment of hepatocellular carcinoma. Liver Transpl 2004;10:S115-S120.

25. Miller AB, Hoogstraten B, Staquet $M$, Winkler A. Reporting results of cancer treatment. Cancer 1981;47:207-14.

26. Llovet JM, Ricci S, Mazzaferro V, Hilgard P, Gane E, Blanc JF, de Oliveira AC, Santoro A, Raoul JL, Forner A, Schwartz M, Porta C, Zeuzem S, Bolondi L, Greten TF, Galle PR, Seitz JF, Borbath I, Häussinger D, Giannaris T, Shan M, Moscovici M, Voliotis D, Bruix J. Sorafenib in advanced hepatocellular carcinoma. N Engl J Med 2008;359:378-90.

27. Bruix J, Sala M, Llovet JM. Chemoembolization for hepatocellular carcinoma. Gastroenterology 2004;127:S179-S188.

28. Leung TWT, Johnson PJ. Systemic therapy for hepatocellular carcinoma. Semin Oncol 2001;28:514-20.

29. Kudo M. Treatment of advanced hepatocellular carcinoma with emphasis on hepatic arterial infusion chemotherapy and molecular targeted therapy. Liver Cancer 2012;1:62-70.

30. Sakon M, Nagano H, Dono K, Nakamori S, Umeshita K, Yamada A, Kawata S, Imai Y, lijima S, Monden M. Combined intraarterial 5-fluorouracil and subcutaneous interferon-alpha therapy for advanced hepatocellular carcinoma with tumor thrombi in the major portal branches. Cancer 2002;94:435-42.

31. Urabe T, Kaneko S, Matsushita E, Unoura M, Kobayashi K. Clinical pilot study of intrahepatic arterial chemotherapy with methotrexate, 5-fluorouracil, cisplatin and subcutaneous interferon-alpha-2b for patients with locally advanced hepatocellular carcinoma. Oncology 1998;55:39-47.

32. Terashima T, Yamashita $T$, Arai $K$, Sunagozaka $H$, Kitahara $M$ Nakagawa H, Kagaya T, Mizukoshi E, Honda M, Kaneko S. Feasibility and efficacy of hepatic arterial infusion chemotherapy for advanced hepatocellular carcinoma after sorafenib. Hepatol Res 2014; 44:117985. doi:10.1111/hepr.12266.

33. Shao YY, Liang PC, Wu YM, Huang CC, Huang KW, Cheng JC, Hsu $\mathrm{CH}$, Hsu C, Cheng AL, Lin ZZ. A pilot study of hepatic arterial infu- 
sion of chemotherapy for patients with advanced hepatocellular carcinoma who have failed anti-angiogenic therapy. Liver Internat 2013;33:1413-9.

34. Miyaki D, Aikata $H$, Kan H, Fujino $H$, Urabe A, Masaki K, Fukuhara T, Kobayashi T, Naeshiro N, Nakahara T, Kawaoka T, Hiramatsu A, Takahashi S, Ishikawa M, Kakizawa H, Awai K, Chayama K. Clinica outcome of sorafenib treatment in patients with advanced hepatocellular carcinoma refractory to hepatic arterial infusion chemotherapy. J Gastroenterol Hepatol 2013;28:1834-41.

35. Jeong SW, Jang JY, Lee JE, Lee SH, Kim SG, Cha SW, Kim YS, Cho YD, Kim HS, Kim BS, Kim KH, Kim YJ. The efficacy of hepatic arterial infusion chemotherapy as an alternative to sorafenib in advanced hepatocellular carcinoma. Asia Pac J Clin Oncol 2012;8:164-71.

36. Melichar B, Dvorak J, Hyspler R, Zadak Z. Intestinal permeability in the assessment of intestinal toxicity of cytotoxic agents. Chemotherapy 2005;51:336-8.

37. Melichar B, Nemcová I. Eye complications of cetuximab therapy. Eur J Cancer Care 2007;16:439-43.

38. Earlam S, Glover C, Davies M, Fordy C, Allen-Mersh TG. Effect of regional and systemic fluorinated pyrimidine chemotherapy on quality of life in colorectal liver metastasis patients. J Clin Oncol 1997; 15:2022-9.

39. Melichar B. Laboratory medicine and medical oncology: the tale of two Cinderellas. Clin Chem Lab Med 2013;51:99-112.
40. Melichar B, Solichova D, Melicharova K, Malirova E, Cermanova M, Zadak Z. Urinary neopterin in patients with advanced colorectal carcinoma. Int J Biol Markers 2006;21:190-8.

41. Melichar B, Jandik P, Krejsek J, Solichova D, Drahosova M, Skopec F, Mergancova J, Voboril Z. Mitogen-induced lymphocyte proliferation and systemic immune activation in cancer patients. Tumori 1996;82:218-20.

42. Melichar B, Touskova M, Solichova D, Kralickova P, Kopecky O. CD4+ T-lymphocytopenia and systemic immune activation in patients with primary and secondary liver tumours. Scand J Clin Lab Inv 2001;61:363-70.

43. Fagan EA, Pulley M, Limb A, Wolstencroft R, Cranenburgh C, De Vinci C, Karani J, Michell M, Nunnerley H, Zaman S. Adoptive immunotherapy administered via the hepatic artery and intralesional interleukin-2 in hepatocellular carcinoma. Cancer Treat Rev 1989;16:151-60.

44. Takayama T, Sekine T, Makuuchi M, Yamasaki S, Kosuge T, Yamamoto J, Shimada K, Sakamoto M, Hirohashi S, Ohashi Y, Kakizoe T. Adoptive immunotherapy to lower postsurgical recurrence rates of hepatocellular carcinoma: a randomized trial. Lancet 2000;356:802-7.

45. Oka M, Hazama S, Yoshino S, Shimoda K, Suzuki M, Shimizu R, Yano K, Nishida M, Suzuki T. Intraarterial combined immunochemotherapy for unresectable hepatocellular carcinoma: preliminary results. Cancer Immunol Immunother 1994;38:194-200. 